\title{
MATHEMATICAL MODEL FOR PREDICTION OF BIOMASS ASH MELTING TEMPERATURE USING ADDITIVES
}

Some types of biomass ash have low ash melting temperature which can result in various problems in combustion processes. Ash slags and sinters can avoid heat transfer in heat exchangers, which can also cause corrosion of heat transfer surfaces. One of the ways of burning fuels with low ash melting temperature is to use additives. Ash melting temperature can be determined in a laboratory on the basis of standard STN ISO 540. Meltability of ash is characterized by the physical state of ash occurring during the heating process under well-defined conditions in the furnace. Experimental determination of ash melting temperature is quite expensive. In this work a prediction method of ash melting temperature is described. The mathematical model uses multiple linear regression where input parameters are the known chemical composition of fuel ash and used additive converted to an amount of $\mathrm{SiO} 2, \mathrm{CaO}, \mathrm{K2O}, \mathrm{MgO}$ and Al2O3. The mathematical model is relatively accurate with real ash melting temperatures and reaches accuracy about of $90 \%$ compared with ash melting temperatures obtained by STN ISO 540 method in a laboratory.

Keywords: Ash melting temperature, biomass ash, additives, prediction.

\section{Introduction}

Biomass is continuously gaining interest as a sustainable energy resource that is available in many forms and can be obtained from different sources [1]. With further development, utilization of bioenergy can be expanded to meet the increasing energy demands, reduce the carbon dioxide emissions and global warming, with the benefit of urban and rural wastes disposal [2]. Currently, biomass combustion still remains the dominant technology for heat and power production [3].

The use of biomass may be connected with problems and limitations. One of these is ash from biofuel which may cause various problems during combustion processes in heating devices [4].

\subsection{Ash related problems during biomass combustion}

Biomass consists of combustible substance, ash and water [5]. Combustible substance is the part of fuel which releases heat by oxidation, i.e., energy is chemically bound in fuel [6]. Ballast of fuel consisting of ash and water is an undesirable proportion of the fuel [7].

Fuel ash is a result of the reaction of minerals presented in biomass. Minerals and other different substances which form ash got into biomass during growth. Ash is a solid residue resulting from the perfect laboratory combustion of fuel. It is composed of minerals that are present in the fuel. In published works [3], [8] and [9] it was found out that silicon, aluminum and iron reach the highest concentration of diversity to make up the ash biomass. Chemically, the ash from biomass is mainly composed of a mixture of oxides of inorganic elements $\mathrm{K}_{2} \mathrm{O}, \mathrm{Na}_{2} \mathrm{O}, \mathrm{CaO}$, $\mathrm{MgO}, \mathrm{Fe}_{2} \mathrm{O}_{3}, \mathrm{Al}_{2} \mathrm{O}_{3}, \mathrm{SiO}_{2}, \mathrm{P}_{2} \mathrm{O}_{5}$ [10]. Amount of ash depends on combustion conditions [11]. The presence of ash forming elements of biomass is the result of chemical processes, intake of minerals from the soil and method of biomass transportation. Some of these elements are necessary for plant growth [12]. Constituent parts of ash biomass are divided into macronutrients (potassium, calcium, magnesium, phosphorus and sulphur) and micronutrients (iron, manganese and chlorine). Silicon, aluminum and sodium are essential for plant growth [13].

Ash in biofuel can avoid heat transfer in heat exchangers, which can cause corrosion of heat transfer surfaces. When using biofuels it is necessary to monitor content of potassium, sodium, sulfur, chlorine and their compounds because during burning they create a molten phase in which the ash particles become sticky and adhere to the heat exchange surface [14]. During combustion of certain types of plant biomass, such as straw, whole plant cereals and hay, the temperature in the combustion chamber ranges from 800 to $900^{\circ} \mathrm{C}$, which exceeds the melting temperature of these fuels. They are, therefore regarded as technically complicated combustible fuels [12]. Maintaining the temperature in the combustion chamber under the ash melting temperature

\footnotetext{
* Michal Holubcik, Jozef Jandacka

Department of Power Engineering, Faculty of Mechanical Engineering, University of Zilina, Slovakia

E-mail: michal.holubcik@fstroj.uniza.sk
} 
(AMT) and avoiding the formation of sinter deposits and slags is quite a complex task. Nevertheless, it is possible to control the combustion temperature at least within certain limits so that the formation of sediments and sinters is significantly limited [15]. Sometimes it is not possible to do constructional modifications. Then, a possible solution to the low AMT of biomass may be the use of additives to the fuel during its production or before its combustion. Additives change the chemical composition of ash, which causes the change in AMT.

\subsection{The aim of the article}

The article deals with the chemical composition of biomass ash changed by the use of various additives and with their influence on AMT. In the next part of the article a method for the prediction of biomass AMT is proposed. The input parameters are weights and chemical compositions of potential biofuel and additive.

\section{Use of additives to increase biomass ash melting temperature}

\subsection{Materials}

3 different types of basic biofuels were used:

- Spruce wood - relative humidity is $10 \%$, calorific value is 16,47 MJ.kg ${ }^{-1}$. Chemical composition: $49.84 \% \mathrm{C}, 6.03 \% \mathrm{H}_{2}$, $43.2 \% \mathrm{O}_{2}, 0.12 \% \mathrm{~N}_{2}, 0.01 \% \mathrm{~S}, 0.005 \% \mathrm{Cl}$.

- Miscanthus giganteus - relative humidity is $10 \%$, calorific

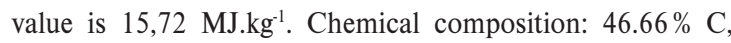
$5,84 \% \mathrm{H}_{2}, 41.7 \% \mathrm{O}_{2}, 0.74 \% \mathrm{~N}_{2}, 0.15 \% \mathrm{~S}, 0.22 \% \mathrm{Cl}$.

- Wheat straw - relative humidity is $12 \%$, calorific value is 15,12 MJ.kg ${ }^{-1}$. Chemical composition: $45.64 \% \mathrm{C}, 5.96 \% \mathrm{H}_{2}, 42.4 \%$ $\mathrm{O}_{2}, 0.73 \% \mathrm{~N}_{2}, 0.082 \% \mathrm{~S}, 0.19 \% \mathrm{Cl}$.

Calorific value of biofuels samples was determined by tests with using of calorimeter LECO AC 500. Chemical compositions of samples were determined in external accredited laboratory. Values of chemical composition are reported for water - free combustible part of samples.

\subsection{Used additives}

An additive is a substance (ingredient) added to some material (product) in order to improve some of its properties [5] In practice, it usually happens that when some characteristics are improved, some deficiencies begin to appear. It is, therefore necessary to analyze the effects of each used ingredient on fuel properties. In compliance with the recommendations in [16], 6 types of additives were used:
- Kaolin - is a white or light-colored unpaved sedimentary rock, formed mostly by decomposition of rocks rich in feldspar. The main ingredient is clayey mineral kaolinite $\mathrm{Si}_{2} \mathrm{Al}_{2} \mathrm{O}_{5}\left(\mathrm{OH}_{4}\right)$ which makes up $80 \%$ of its capacity.

- Talc - is a white mineral composed of hydrated magnesium silicate with the chemical formula $\mathrm{H}_{2} \mathrm{Mg}_{3}\left(\mathrm{SiO}_{3}\right)_{4}$ or $\mathrm{Mg}_{3} \mathrm{Si}_{4} \mathrm{O}_{10}(\mathrm{OH})_{2}$.

- Limestone - or calcium oxide $(\mathrm{CaO})$ is a white, caustic, alkaline crystalline solid at room temperature [17].

- Lime - is a sedimentary rock composed largely of the minerals calcite and aragonite which are different crystal forms of calcium carbonate $\left(\mathrm{CaCO}_{3}\right)$.

- Dolomite - is a carbonate mineral composed of calcium magnesium carbonate $\mathrm{CaMg}\left(\mathrm{CO}_{3}\right)_{2}$. The term is also used to describe the sedimentary carbonate rock dolostone.

- Bentonite - is an absorbent aluminum phyllosilicate, essentially impure clay consisting mostly of montmorillonite. There are different types of bentonite, each named after the respective dominant element, such as potassium $(\mathrm{K})$, sodium $(\mathrm{Na})$, calcium $(\mathrm{Ca})$, and aluminum $(\mathrm{Al})$. For the purpose of this paper $\mathrm{Al}$ - bentonite was used.

\subsection{Methodology of sample preparation}

Pelletizing was chosen to provide good distribution of additive in biofuel. Pellets production is a complex process in which the starting material must meet certain conditions [18]. It cannot contain undesirable objects. The biggest size of sawdust fraction must be smaller than a diameter of holes in the matrix of pellet mill [19]. The humidity of input material should be around $15 \%$. Manufactured pellets must be cooled and stored properly.

In the laboratory of the University of Zilina an experimental device for pelletizing has been designed and implemented. The device consists of an input material tank (in which biomass for production of pellets is delivered), a crusher (which crushes material to fractions of size max. $4 \mathrm{~mm}$ in accordance with the recommendations in [3]), a crushed material tank (where the crushed material is temporarily stored), a dryer (where wet material is dried for optimal humidity), a mixing machine with capacity of $50 \mathrm{dm}^{3}$ (where dried material is mixed with water to relative humidity of about $15-20 \%$ in accordance with the recommendation in [11] and an additive in amount of $2 \%$ ), a pellet mill with capacity of $70-100 \mathrm{~kg} \cdot \mathrm{h}^{-1}$ (where the material prepared from biomass is pressed to pellets), a cooler and a duster with fan (final product - pellets are cooled to room temperature and dusted), and a produced pellets tank (where pellets are temporarily stored before packing).

18 samples of pellets with $2 \%$ addition of various additives from 3 different biomass fuels and 3 samples without additives were made- reference samples (wood pellets, miscanthus pellets and straw pellets). 


\section{Methods of experiments}

The AMTs and chemical compositions of ash for selected samples were experimentally determined on the basis of results in [3].

\subsection{Ash melting temperature}

AMT of produced samples was determined on the basis of standard STN ISO 540. Meltability of ash is characterized by the physical state of the ash occurring during the heating process under well-defined conditions in the furnace [20]. The following temperatures were monitored during the melting of ash:

1. Shrinkage temperature (ST) - is the temperature at which first symptoms of rounded edges or the edges of the test specimen occur due to melting.

2. Deformation temperature (DT) - is the temperature at which the edges of the test specimen are completely rounded, without changing the amount.

3. Hemisphere temperature (HT) - is the temperature at which the test specimen creates a hemisphere, the amount of which is equal to about half the base.

4. Flow temperature (FT) - is the temperature at which the ash spreads on a base to such a layer whose amount is approximately one third of the test specimen at the melting temperature.

Resulting value of AMT was determined by averaging 2 AMT measurements for each sample.

\subsection{Chemical composition of ash}

Chemical compositions of ash were determined using inductively coupled plasma with atomic emission spectroscopy (ICP-AES) in an off-campus laboratory. The sample was melted to meet the required elements. The ICP-AES analysis requires adhibition of elements to be analyzed in argon plasma induced by high frequency where the temperature ranges from 8000 to $10000{ }^{\circ} \mathrm{C}$. The sample in aerosol form was put into the plasma where it was excited. Each excited particle of an element emits a characteristic spectrum of light (qualitative analysis) which is captured by the optical system of the spectrometer and further processed electronically. The intensity of the emitted radiation is directly proportional to the amount of this element in the sample (quantitative analysis). Amounts of silicon dioxide $\left(\mathrm{SiO}_{2}\right)$, calcium oxide $(\mathrm{CaO})$, magnesium oxide $(\mathrm{MgO})$, aluminium oxide $\left(\mathrm{Al}_{2} \mathrm{O}_{3}\right)$ and potassium oxide $\left(\mathrm{K}_{2} \mathrm{O}\right)$ were determined.

Resulting value of $\mathrm{SiO}_{2}, \mathrm{CaO}, \mathrm{MgO}, \mathrm{Al}_{2} \mathrm{O}_{3}$ and $\mathrm{K}_{2} \mathrm{O}$ amount was determined by averaging 2 measurements for each sample.

\section{Results of experiments}

Table 1 shows average values of AMTs and amounts of $\mathrm{SiO}_{2}$, $\mathrm{CaO}, \mathrm{MgO}, \mathrm{Al}_{2} \mathrm{O}_{3}$ and $\mathrm{K}_{2} \mathrm{O}$.

The results in Table 1 show that addition of some additives can change chemical composition of ash and increase AMT. The increase of AMT can help reduce problems with ash sintering during combustion of some types of biofuels.

Average values of AMTs and amounts of $\mathrm{SiO}_{2}, \mathrm{CaO}, \mathrm{MgO}, \mathrm{Al}_{2} \mathrm{O}_{3}$ and $\mathrm{K}_{2} \mathrm{O}$

Table 1

\begin{tabular}{|l|c|c|c|c|c|c|c|c|c|}
\hline Sample & $\mathrm{ST}\left[{ }^{\circ} \mathrm{C}\right]$ & $\mathrm{DT}\left[{ }^{\circ} \mathrm{C}\right]$ & $\mathrm{HT}\left[{ }^{\circ} \mathrm{C}\right]$ & $\mathrm{FT}\left[{ }^{\circ} \mathrm{C}\right]$ & $\mathrm{SiO}_{2}[\%]$ & $\mathrm{CaO}[\%]$ & $\mathrm{MgO}[\%]$ & $\mathrm{Al}_{2} \mathrm{O}_{3}[\%]$ & $\mathrm{K}_{2} \mathrm{O}[\%]$ \\
\hline Wood (reference) & 1170 & 1212 & 1219 & 1231 & 49.5 & 19.84 & 4.0 & 5.67 & 7.76 \\
\hline Wood + kaolin & 1283 & 1302 & 1324 & 1416 & 29.84 & 9.47 & 1.59 & 20.41 & 3.2 \\
\hline Wood + talc & 1258 & 1310 & 1355 & 1458 & 25.76 & 8.74 & 16.82 & 2.58 & 2.82 \\
\hline Wood + lime & 1302 & 1362 & 1416 & 1482 & 8.19 & 67.3 & 5.22 & 2.25 & 2.36 \\
\hline Wood + limestone & 1318 & 1354 & 1424 & 1517 & 8.59 & 49.91 & 5.44 & 2.32 & 2.94 \\
\hline Wood + dolomite & 1361 & 1452 & 1560 & 1638 & 8.37 & 38.13 & 18.35 & 2.08 & 3.25 \\
\hline Wood + bentonite & 1129 & 1157 & 1187 & 1377 & 42.26 & 9.65 & 4.89 & 13.13 & 3.49 \\
\hline Miscanthus (reference) & 940 & 980 & 1170 & 1190 & 54.4 & 4.7 & 2.72 & 0.22 & 20.37 \\
\hline Miscanthus + kaolin & 1187 & 1215 & 1238 & 1319 & 33.79 & 9.25 & 1.85 & 19.81 & 8.36 \\
\hline Miscanthus + lime & 1171 & 1231 & 1240 & 1268 & 17.34 & 14.88 & 3.87 & 0.25 & 4.95 \\
\hline Miscanthus + dolomite & 1131 & 1189 & 1218 & 1250 & 21.38 & 11.8 & 8.23 & 0.31 & 6.05 \\
\hline Straw (reference) & 915 & 941 & 1111 & 1226 & 64.3 & 5.4 & 1.8 & 0.3 & 17.0 \\
\hline Straw + kaolin & 1146 & 1227 & 1261 & 1337 & 47.18 & 5.78 & 2.31 & 21.34 & 10.76 \\
\hline Straw + lime & 1193 & 1223 & 1240 & 1280 & 38.93 & 18.51 & 4.56 & 0.42 & 9.41 \\
\hline Straw + dolomite & 1111 & 1133 & 1165 & 1235 & 38.32 & 10.5 & 7.94 & 0.51 & 10.19 \\
\hline Straw + bentonite & 1003 & 1142 & 1217 & 1318 & 43.76 & 5.60 & 3.67 & 11.74 & 8.59 \\
\hline
\end{tabular}


The highest AMT of spruce wood was achieved by adding $2 \%$ of dolomite where ST was higher by $16.3 \%$, DT higher by $19.8 \%$, HT higher by $27.9 \%$ and HT higher by $33.1 \%$ in comparison with the reference sample. The addition of kaolin had the most positive impact on the AMT of miscanthus giganteus or wheat straw; the AMT increased on average by $15.9 \%$ or by $18.6 \%$, in comparison with the reference sample.

In terms of chemical composition of biomass samples it can generally be argued that the higher amount of $\mathrm{CaO}$ and $\mathrm{MgO}$ at the expense of the lower amount of $\mathrm{SiO}_{2}$ and, mainly, of $\mathrm{K}_{2} \mathrm{O}$ (probably the most negative compound in terms of AMT), increases the AMT of some types of biofuels.

\section{Mathematical model for prediction of biomass ash melting temperature using additives}

To obtain a correlation for calculating biomass AMT, the proposed mathematical model uses a multiple linear regression [3] which examines the relationship between several variables. It was necessary to choose the method of least squares to minimize the sum of squares of residues. The proposed mathematical model was inspired by works [16], [21], [22] and [23].

Inlet values are weight contents of $\mathrm{SiO}_{2}, \mathrm{CaO}, \mathrm{K}_{2} \mathrm{O}, \mathrm{MgO}$ and $\mathrm{Al}_{2} \mathrm{O}_{3}$ in a basic biofuel (for example, spruce wood) and weight contents of $\mathrm{SiO}_{2}, \mathrm{CaO}, \mathrm{K}_{2} \mathrm{O}, \mathrm{MgO}$ and $\mathrm{Al}_{2} \mathrm{O}_{3}$ in an added additive (for example, dolomite). Weight contents of compounds in biofuel with additive are calculated:

$m_{\mathrm{SiO}_{2}}=m_{\text {fuel }} \cdot A_{d} \cdot \% \mathrm{SiO}_{2}+m_{\text {adit }} \cdot \%_{\text {adit }} \mathrm{SiO}_{2}$

$m_{\text {CaO }}=m_{\text {fuel }} \cdot A_{d} \cdot \% \mathrm{CaO}+m_{\text {adit }} \cdot \%_{\text {adit }} \mathrm{CaO}$

$m_{K_{2} O}=m_{\text {fuel }} \cdot A_{d} \cdot \% K_{2} O+m_{\text {adit }} \cdot \%_{\text {adit }} K_{2} O$
$m_{M g O}=m_{\text {fuel }} \cdot A_{d} \cdot \% M g O+m_{\text {adit }} \cdot \%_{\text {adit }} M g O$

$m_{\mathrm{Al}_{2} \mathrm{O}_{3}}=m_{\text {fuel }} \cdot A_{d} \cdot \% \mathrm{~A}_{2} \mathrm{O}_{3}+m_{\text {adit }} \cdot \%_{\text {adit }} \mathrm{A}_{2} \mathrm{O}_{3}$

where $\mathrm{m}_{\text {fuel }}[\mathrm{g}]$ is the weight of biofuel, $\mathrm{A}_{\mathrm{d}}[\%]$ is the ash content in biofuel (in accordance with STN EN 14775), \% $\left(\mathrm{SiO}_{2}, \mathrm{CaO}, \mathrm{K}_{2} \mathrm{O}\right.$, $\mathrm{MgO}, \mathrm{Al}_{2} \mathrm{O}_{3}$ ) [\%] is the amount of $\mathrm{SiO}_{2}, \mathrm{CaO}, \mathrm{K}_{2} \mathrm{O}, \mathrm{MgO}, \mathrm{Al}_{2} \mathrm{O}_{3}$ in biofuel ash, $\mathrm{m}_{\text {adit }}[\mathrm{g}]$ is the amount of used additive, $\%{ }_{\text {adit }}\left(\mathrm{SiO}_{2}\right.$, $\mathrm{CaO}, \mathrm{K}_{2} \mathrm{O}, \mathrm{MgO}, \mathrm{Al}_{2} \mathrm{O}_{3}$ ) [\%] is the amount of $\mathrm{SiO}_{2}, \mathrm{CaO}, \mathrm{K}_{2} \mathrm{O}$, $\mathrm{MgO}, \mathrm{Al}_{2} \mathrm{O}_{3}$ in used additive.

To increase the accuracy of the mathematic model the following 3 factors were created:

Dolomite index $\left(\mathrm{D}_{\mathrm{IXm}}\right)$ - determines the weight proportion of dolomitic compounds $(\mathrm{CaO}$ and $\mathrm{MgO})$ to the sum of the amounts of $\mathrm{SiO}_{2}, \mathrm{CaO}, \mathrm{K}_{2} \mathrm{O}, \mathrm{MgO}$ and $\mathrm{Al}_{2} \mathrm{O}_{3}$ in biomass ash

$D_{\mathrm{IXm}}=\frac{m_{\mathrm{CaO}}+m_{\mathrm{MgO}_{\mathrm{O}}}}{m_{\mathrm{SiO}_{2}}+m_{\mathrm{CaO}}+m_{\mathrm{K}_{2} \mathrm{O}}+m_{\mathrm{MgO}}+m_{\mathrm{Al}_{2} \mathrm{O}_{2}}}$

Factor $\mathrm{CMK}$ - the ratio of the sum of $\mathrm{CaO}$ and $\mathrm{MgO}$ weight content to $\mathrm{K}_{2} \mathrm{O}$ weight content in biomass ash

$f_{C M K m}=\frac{m_{\mathrm{CaO}}+m_{\mathrm{MgO}}}{m_{K_{2} \mathrm{O}}}$

Factor $\mathrm{PH}$ - the ratio of the weight sum of basic $\left(\mathrm{CaO}, \mathrm{K}_{2} \mathrm{O}\right.$, $\mathrm{MgO})$ and acidic $\left(\mathrm{SiO}_{2}, \mathrm{Al}_{2} \mathrm{O}_{3}\right)$ compounds in biomass ash

$f_{\mathrm{PHm}}=\frac{m_{\mathrm{CaO}}+m_{\mathrm{K}_{2} \mathrm{O}}+m_{\mathrm{MgO}_{\mathrm{g}}}}{m_{\mathrm{SiO}_{2}}+m_{\mathrm{Al}_{2} \mathrm{O}_{3}}}$

The equation for AMT (ST, DT, HT, FT) prediction under reducing atmosphere is:

$t=b_{0}+b_{1} \cdot m_{\mathrm{SiO}_{2}}+b_{2} \cdot m_{\mathrm{CaO}}+b_{3} \cdot m_{K_{2} \mathrm{O}}+b_{4} \cdot m_{\mathrm{MgO}}+$

$+b 5 \cdot m_{\mathrm{Al}_{2} \mathrm{O}_{3}}+b_{6} \cdot D_{\mathrm{IXm}}+b_{7} \cdot f_{\mathrm{CMKm}}+b_{8} \cdot f_{\mathrm{PHm}}$

Constant $\mathrm{b}_{0}\left[{ }^{\circ} \mathrm{C}\right]$, the regression coefficients $\mathrm{b}_{1}-\mathrm{b}_{8}\left[{ }^{\circ} \mathrm{C}\right]$, standard deviation $\sigma$ and correlation index $\mathrm{R}$ for prediction of AMT of ST, DT, HT and FT are illustrated in Table 2.

Regression coefficients for prediction of AMT

Table 2

\begin{tabular}{|l|l|c|c|c|l|}
\hline Coef. & Indication. & Variables & DT & ST & HT \\
\hline $\mathbf{b}_{\mathbf{0}}$ & constant & 1093.191937 & 1099.834412 & 1128.7016 & 1194.585516 \\
\hline $\mathbf{b}_{\mathbf{1}}$ & $m_{\text {SiO2 }}$ & -3.081022249 & 1.329223672 & 1.49702109 & 10.10272854 \\
\hline $\mathbf{b}_{\mathbf{2}}$ & $m_{\text {CaO }}$ & 6.65923753 & 3.406691792 & -6.680170818 & -11.02965381 \\
\hline $\mathbf{b}_{\mathbf{3}}$ & $m_{\text {K2O }}$ & -14.91887671 & -25.57010491 & -5.184487742 & -32.62187073 \\
\hline $\mathbf{b}_{\mathbf{4}}$ & $m_{M g O}$ & 0.579373798 & -1.277753798 & -4.628135914 & -2.346833511 \\
\hline $\mathbf{b}_{\mathbf{5}}$ & $m_{A 203}$ & 12.62898213 & 13.44301574 & 7.58442836 & 5.377643061 \\
\hline $\mathbf{b}_{\mathbf{6}}$ & $D_{I X m}$ & 385.3944151 & 488.614852 & 379.7246862 & 238.4313286 \\
\hline $\mathbf{b}_{\mathbf{7}}$ & $f_{\text {CMKm }}$ & -1.420007209 & -2.563995809 & 2.022658794 & 7.698079425 \\
\hline $\mathbf{b}_{\mathbf{8}}$ & $f_{\text {PHm }}$ & -22.44450524 & -15.34711914 & 10.89210758 & 19.24253498 \\
\hline $\mathbf{\sigma}\left[{ }^{\circ} \mathbf{C}\right]$ & & 58.83 & 53.13 & 55.87 & 69.30 \\
\hline $\mathbf{R}$ & & 0.915 & 0.934 & 0.905 & 0.882 \\
\hline
\end{tabular}


Calculated values of ash melting temperatures obtained using the equation (9) together with the correlation coefficients in Table 2 are very accurate because the standard deviation $\sigma$ of all biomass ash melting temperatures is lower than $70^{\circ}$ $\mathrm{C}$, which is below the limit value of the reproducibility of the experiment (STN ISO 540). High accuracy of the mathematic model confirms high levels of correlation index $\mathrm{R}$ exceeding the value of 0.9 , except for one temperature (HT determination, $\mathrm{R}$ $=0.882$ ). In comparison with a similar mathematical model in [22] the proposed mathematical model for AMT prediction is very accurate.

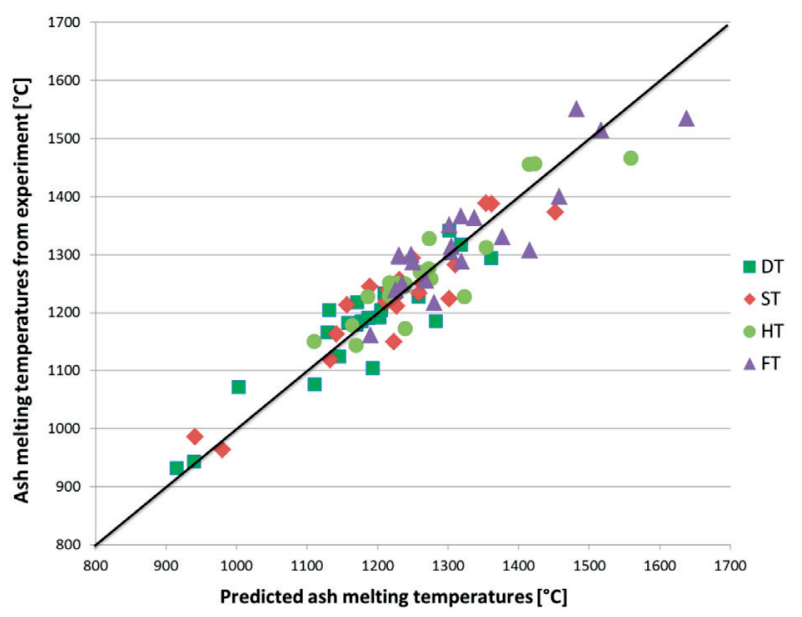

Fig. 1 Comparison of AMT from experiment and predicted AMT
The high accuracy of the model is also confirmed by Fig. 1 which compares the real values of biomass AMT gathered from experimental measurements with those obtained from the mathematical model.

\section{Conclusion}

The use of additives can be a highly interesting and effective way how to solve problems arising from combustion of biofuels with low ash melting temperature. Based on the above mentioned results we can argue that the addition of dolomite and kaolin increased most significantly the AMT of tested biofuels. It was caused by the change in chemical composition of biofuel ash. Empirical equations in the proposed mathematical model were derived from the AMT values gathered in reducing atmosphere. The mathematic model can be used with a small standard deviation for various types of biofuels with various ash chemical compositions. It can also be used for prediction of AMT biomass with addition of various types of additives with known chemical composition. The proposed mathematical model can help to choose a suitable additive for combustion of problematic biomass in practice.

\section{Acknowledgement}

This work is supported by the financial assistance of the project APVV-0458-11

\section{References}

[1] WANG, L., HUSTAD, J., SKREIBERG, O., SKJEVRAK, G., GRONLI, M.: A Critical Review on Additives to Reduce Ash Related Operation Problems in Biomass Combustion Applications, Energy Procedia, vol. 20, 2012, 20-29.

[2] BUCZYNSKI, R., WEBER, R., SZLEK, A., NOSEK, R.: Time-dependent Combustion of Solid Fuels in a Fixed-bed: Measurements and Mathematical Modeling, Energy and Fuels, 26, 8, 2012, 4767-4774.

[3] HOLUBCIK, M.: Possibilities of Increasing Ash Melting Temperature from Biomass (in Slovak), PhD thesis, University of Zilina, 2013.

[4] LABAJ, J., PATSCH, M., BARTA D.: Combustion of Alternative Fuels, Proc. of TRANSCOM 2009, University of Zilina, 2009, 67-76.

[5] SOOS, L., KOLEJAK, M., URBAN, F.: Biomass - Renewable Energy Source (in Slovak), Vert: Bratislava, 2012.

[6] PILAT, P., PATSCH, M., MALCHO, M.: Solar Heat Utilization for Adsorption Cooling Device, EPJ Web of Conferences, vol. 25, 2012.

[7] URBAN, F., KUCAK, L., BEREZNAI, J., PULMANN, M., TYHANYI, J.: Influence of the Mixing Grid Position on the Coolant Flow at the Outflow Part of the Nuclear Reactor Fuel Assembly Physical Model and Validation of CFD Model, Communications - Scientific Letters of the University of Zilina, vol. 14, No. 4a, 42-46. ISSN 1335-4205.

[8] WERKELIN, J., SKRIFVARS, B., HUPA, M.: Ash-Forming Elements in Four Scandinavian Wood Species, Biomass And Bioenergy, vol. 29, No. 6, 2005, 451-466.

[9] BOSTROM, D.: Slagging Characteristics during Combustion of Corn Stovers with and without Kaolin and Calcite. Energy and Fuels, 22, (Compendex), 2008, 3465-3470.

[10] HUZVAR, J., KAPJOR, A.: Micro-cogeneration incl. the Conversion of Chemical Energy of Biomass to Electric Energy and the Low Potential Heat, Proc. of AIP Conference, vol. 1337, 2011, 40-42. 
[11] RIMAR, M., KUNA, S.: Comparison of Methods of Wood Chip Moisture Evaluation, Advanced Materials Research, vol. 724-725, 222-225.

[12] ZEVENHOVEN, M.: Ash-Forming Matter, Biomass Fuels. Abo/Turku: Faculty of Chemical Engineering: Abo Akademi University, 2001, $88 \mathrm{p}$.

[13] ORZECHOWSKI, T., ORMAN, L. J.: Thermovision Inspection of Air Polluting Emitters, Pollution Engineering, vol. 38, 7, 22-25, 2006.

[14] VITAZEK, I., VITAZKOVA, B., PLOTH, J.: Production of Gas Emissions from Biomass Heat Source. Engineering Mechanics, vol. 20, 2013, No. 3/4, 289-298. ISSN 1805-4633.

[15] NEMEC, P., MAlChO, M., SMITKA, M., MATUSOV, J.: Performance Parameters of a Closed Loop Thermosyphon, Communications - Scientific Letters of the University of Zilina, vol. 14, No. 4a, 53-57.

[16] LIORENTE, M. J. F., AROCAS, P. D., NEBOT, L. G., GARCIA, J. E. C., The Effect of the Addition of Chemical Materials on the Sintering of Biomass Ash. Fuel, 87, 12 2008, 2651-2658.

[17] LELOVICS, H., LIPTAKOVA, T.: Time and Mixing Technique-dependent Changes in Bone Cement SmartSet (R) HV, Acta of Bioengineering and Biomechanics, vol. 12, No. 4, 63-67, 2010.

[18] CERNECKY, J., NEUPAUEROVA, A., JANOSKO, I., SOLDAN, M.: Environmental Technology (in Slovak), Technicka univerzita: Zvolen, 274 p., 2010.

[19] TAUS, P., TAUSOVA, M.: Economic Analysis of FV Power Plants According Installed Performance, Acta Montanistica Slovaca, vol. 14, No. 1, 2009

[20] HORAK, J., JANKOVSKA, Z., STRAKA, F., BURYAN, P., KUBESA, P., HOPAN, F., KRPEC, K.: Problems of Determination of Characteristic Temperatures of Biomass Ash Fusibility (in Czech), Chemicke listy, vol. 107, No. 6, 2013, 502-509. ISSN 00092770.

[21] SEGGIANI, M.: Empirical Correlations of the Ash Fusion Temperatures and Temperature of Critical Viscosity for Coal and Biomass Ashes, Fuel, vol. 78, 1999, 1121-1125

[22] LIORENTE, M. J. F, GARCIA, J. E. C.: Comparing Methods for Predicting the Sintering of Biomass Ash in Combustion, Fuel, 84, 2005, 1893-1900

[23] NEMEC, P., CAJA, A., MALCHO, M.: Mathematical Model for Heat Transfer Limitations of Heat Pipe, Mathematical and Computer Modelling, vol. 57, No. 1-2, 2013, 126-136. 